\title{
Lessons learned from the COVID-19 pandemic: Why we need to invest in
}

\section{advanced practice nurses}

Dear Editor:

In recognition of the newly gained prominence and visibility of health professionals in the fight against the COVID-19 pandemic, the World Health Organization has made 2021 the International Year of Health and Care Workers, after having designated 2020 as the International Year of the Nurse and the Midwife.

Nurses are essential at the different levels of health care, following best practices, offering timely information and action in health, and coordinating and managing care and services. However, investment in nursing professionals has proven to be insufficient; efforts must be made to strengthen leadership and optimize this workforce for an effective response to the health needs of the population.

The Pan American Health Organization (PAHO) has fostered initiatives to promote the education, hiring, and regulation of advanced practice nurses (APNs) as a strategy to increase people's access to a nursing professional at the first level of primary health care services-one with greater capacity and independence in decision-making and in the diagnosis and treatment of patients according to their needs (1).

These professionals can play a strategic role in addressing health access barriers and in attending to the health needs of the population, especially groups living in conditions of vulnerability, in rural and remote communities, and in places with a low density of other health professionals. Beyond the important role they play in the health services and on the front lines of the pandemic, their activities can be expanded through adequate training, regulation, and interdisciplinary work. Several countries have introduced advanced roles for nurses (2), but this is not the general situation in Latin America.

The work of APNs in hospital settings has been associated with shorter patient stays, greater coordination, more collaborative work, faster responses, reduced mortality, and greater satisfaction among critical-care patients (3). In primary care settings, APNs are associated with disease prevention, health promotion, and the care of patients with chronic conditions (4).

During the pandemic, services provided in homes and in the community have helped reduce demand for hospital and emergency services related to COVID-19 and other conditions. They have also expanded access to vulnerable patients and supported patient rehabilitation and recovery (5).
The work of nurses has resulted in lower COVID-19 infection rates among residents in long-term care institutions in the United States (6), and has reduced mortality rates and hospital readmission for up to 30 days for patients in home treatment with use of oxygen and continuous telephone support (7). Remote and telehealth services have benefited remote communities (8) and enabled respiratory system monitoring and support for rehabilitation and mental health in patients recovering from COVID-19 (5).

Nurses took innovative approaches to care delivery, developed new workflows, and helped with the integration of the health services, while dealing with other concerns such as personal and family exposure to the virus, death of colleagues, and scarcity of personal protective equipment.

APNs have taken a leading role in the management of individual and family care, health training and education, advocacy for patients, and establishment of effective communication among various professionals, as well as in actions focused on quality of care, professional practice, building skills and competencies, expansion of critical knowledge, decision-making, collaboration, and establishment of effective partnerships (9). Nurses have also played a role as researchers.

Despite their contributions, there is a lack of clarity about their roles and functions and an inadequate regulatory structure (2). Out-of-date regulatory frameworks may compromise their entry into the labor market.

The pandemic has greatly affected the productive, economic, and educational sectors, with the greatest impact on populations in conditions of vulnerability, which are precisely those that may benefit the most from the work of APNs.

The educational sector should prepare professionals capable of responding to the health needs of the population, with upgraded clinical skills and knowledge in the areas of pharmacology, physiology, diagnosis, and treatment, in addition to receiving continuous education in the workplace. Professional regulations should ensure that they are able to engage in all aspects of professional practice.

Considering labor shortages, unequal distribution of human resources, broad participation of nursing professionals in the health sector, new regional and global guidelines that aim for greater investment in the nursing workforce, and the global situation brought about by the COVID-19 pandemic, Latin American countries should be prepared to invest in education, the labor market, and the deployment 
of APNs in health services at the first level of care. It is an investment that will show rapid results with relatively low costs. It is also a strategy to reduce pressure on health systems and is a viable way to care for groups in conditions of greatest vulnerability.

WHO's Global strategic directions for nursing and midwifery 2021-25 focuses on strengthening the workforce in nursing and midwifery in order to achieve universal health coverage and other health goals for the population. It proposes the adoption of political priorities focused on investment in education, jobs, and leadership, and on maximizing the contributions of nurses in the workplace (10).

The newly gained visibility and social esteem of nursing has created favorable political, social, and organizational conditions for the introduction or improvement of advanced nursing practices. The economic sector will certainly also benefit from greater participation of women in health and an expanded supply of innovative courses.
Conflicts of interest. None declared.

Disclaimer. The author holds sole responsibility for the views expressed in the manuscript, which may not necessarily reflect the opinion or policy of the RPSP/PAJPH and/or PAHO.

\section{Silvia Helena De Bortoli Cassiani}

Pan American Health Organization/World Health Organization, Washington, D.C., United States of America $₫$ cassianis@paho.org

\section{Bruna Moreno Dias}

Pan American Health Organization/World Health Organization, Washington, D.C., United States of America https: / orcid. org/0000-0002-7346-4848

Suggested citation Cassiani SHB, Dias BM. Lessons learned from the COVID-19 pandemic: Why we need to invest in advanced practice nurses. Rev Panam Salud Publica. 2021;45:e92. https://doi.org/10.26633/RPSP. 2021.92

\section{REFERENCES}

1. Pan American Health Organization. Expanding the Roles of Nurses in Primary Health Care [Internet]. Washington D. C.: PAHO; 2018. Available from: https: / / iris.paho.org/handle/10665.2/34958. Accessed 19 August 2020

2. Maier CB, Aiken LH, Busse R. Nurses in advanced roles in primary care. OECD Health Working Papers. 2017;98. Paris: OECD Publishing; 2017. Available from: https://www.oecd-ilibrary.org/content/ paper/a8756593-en

3. Woo BFY, Lee JXY, Tam WWS. The impact of the advanced practice nursing role on quality of care, clinical outcomes, patient satisfaction, and cost in the emergency and critical care settings: a systematic review. Hum Resour Health [Internet]. 2017;15(1):63. Available from: http://human-resources-health.biomedcentral. com/articles/10.1186/s12960-017-0237-9. Accessed 19 August 2020

4. Hämel K, Toso BRG de O, Casanova A, Giovanella L. Advanced Practice Nursing in Primary Health Care in the Spanish National Health System. Cien Saude Colet [Internet]. 2020;25(1):303-14. Available from: http://www.scielo.br/scielo.php?script=sci_art text\&pid=S1413-81232020000100303\&tlng=en. Accessed 19 August 2020

5. Park S, Elliott J, Berlin A, Hamer-Hunt J, Haines A. Strengthening the UK primary care response to covid-19. BMJ [Internet]. 2020 Sep 25;m3691. Available from: https://www.bmj.com/lookup/ doi /10.1136/bmj.m3691. Accessed 19 August 2020

6. Figueroa JF, Wadhera RK, Papanicolas I, Riley K, Zheng J, Orav EJ, et al. Association of Nursing Home Ratings on Health Inspections, Quality of Care, and Nurse Staffing With COVID-19 Cases. JAMA
[Internet]. 2020;324(11):1103. Available from: https://jamanetwork. com/journals/jama/fullarticle/2769437. Accessed 19 August 2020

7. Banerjee J, Canamar CP, Voyageur C, Tangpraphaphorn S, Lemus A, Coffey C, et al. Mortality and Readmission Rates Among Patients With COVID-19 After Discharge From Acute Care Setting With Supplemental Oxygen. JAMA Netw Open [Internet]. 2021;4(4):e213990. Available from: https: / /jamanetwork.com/journals/jamanet workopen/fullarticle/2778078. Accessed 19 August 2020

8. McCullough K, Whitehead L, Bayes S, Williams A, Cope V. The delivery of Primary Health Care in remote communities: A Grounded Theory study of the perspective of nurses. Int J Nurs Stud [Internet]. 2020;102:103474. Available from: https://linkinghub.elsevier.com/ retrieve/ pii/S0020748919302810. Accessed 19 August 2020

9. Lamb A, Martin-Misener R, Bryant-Lukosius D, Latimer M. Describing the leadership capabilities of advanced practice nurses using a qualitative descriptive study. Nurs Open [Internet]. 2018;5(3):400-13. Available from: http://doi.wiley.com/10.1002/nop2.150. Accessed 19 August 2020

10. World Health Organization. Global strategic directions for nursing and midwifery 2021-25. Draft for Consultation. Geneva: WHO; 2021.

Manuscript received on 4 June 2021. Not peer-reviewed. Accepted on 17 June 2021. 